\title{
Comparison of coating processes in the development of aluminum-based barriers for blanket applications
}

\author{
S.-E. Wulf, W. Krauss, J. Konys
}

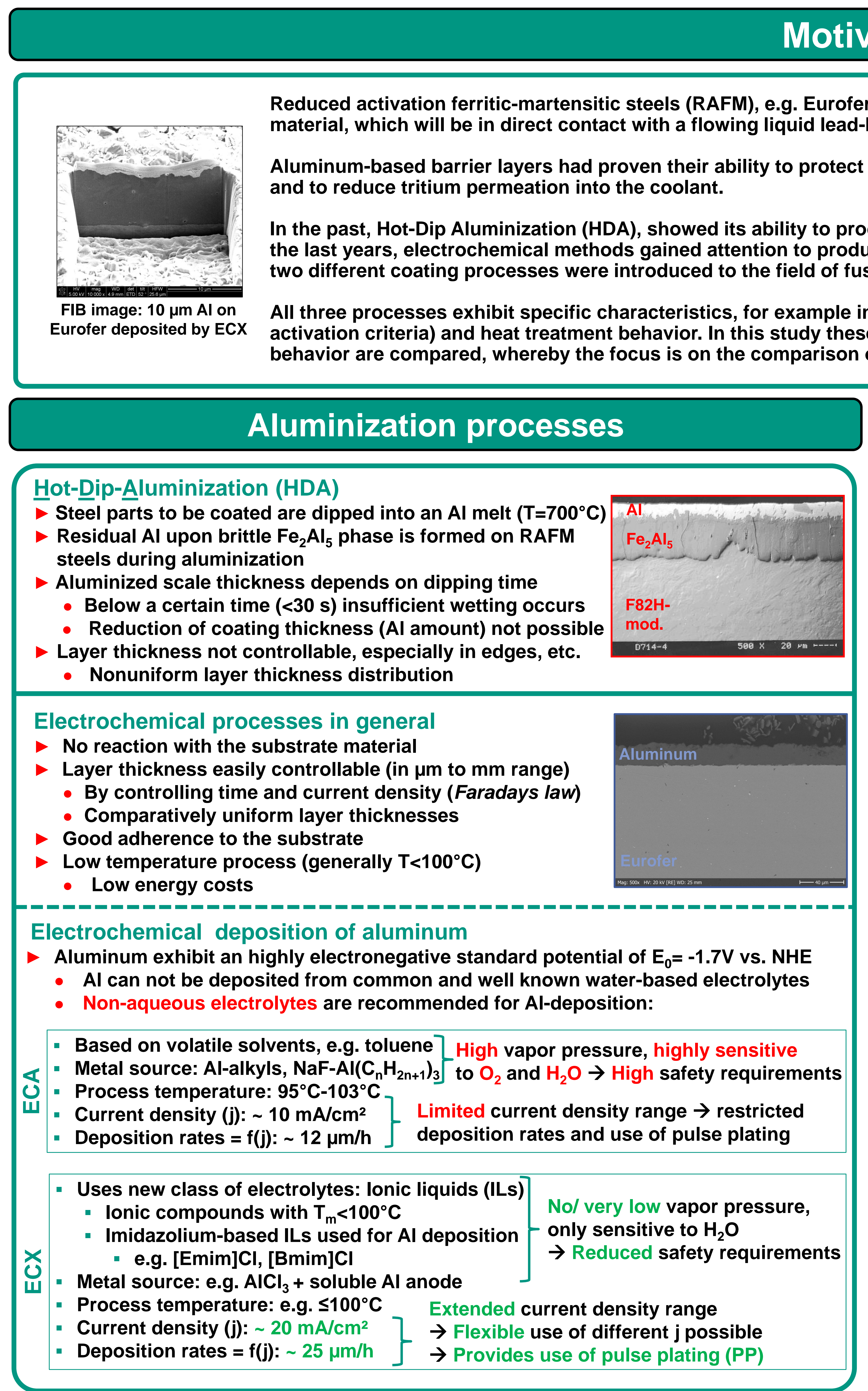

Electrodeposited Aluminum made by ECA and ECX
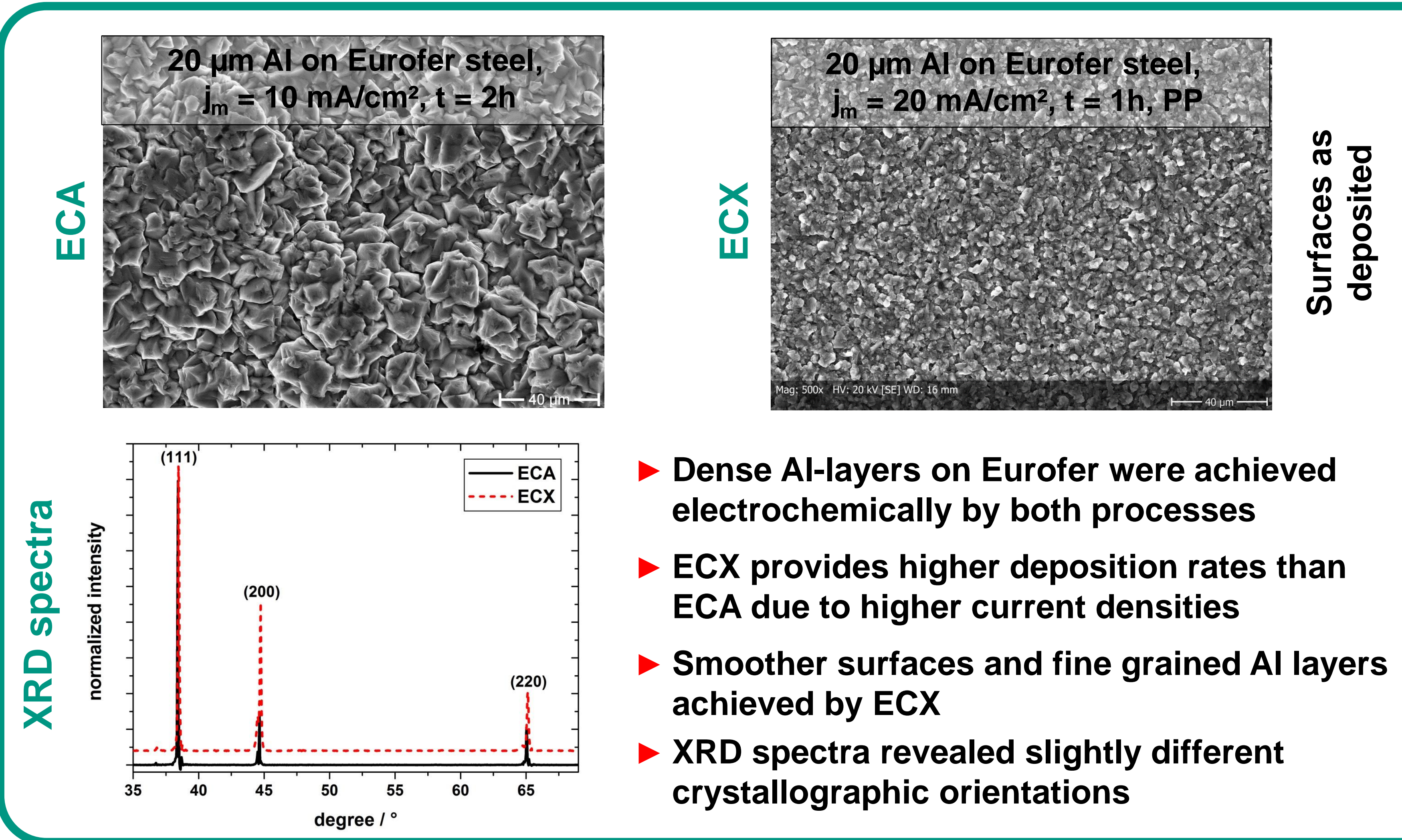

Dense Al-layers on Eurofer were achieved electrochemically by both processes

- ECX provides higher deposition rates than ECA due to higher current densities

Smoother surfaces and fine grained Al layers achieved by ECX

XRD spectra revealed slightly different crystallographic orientations

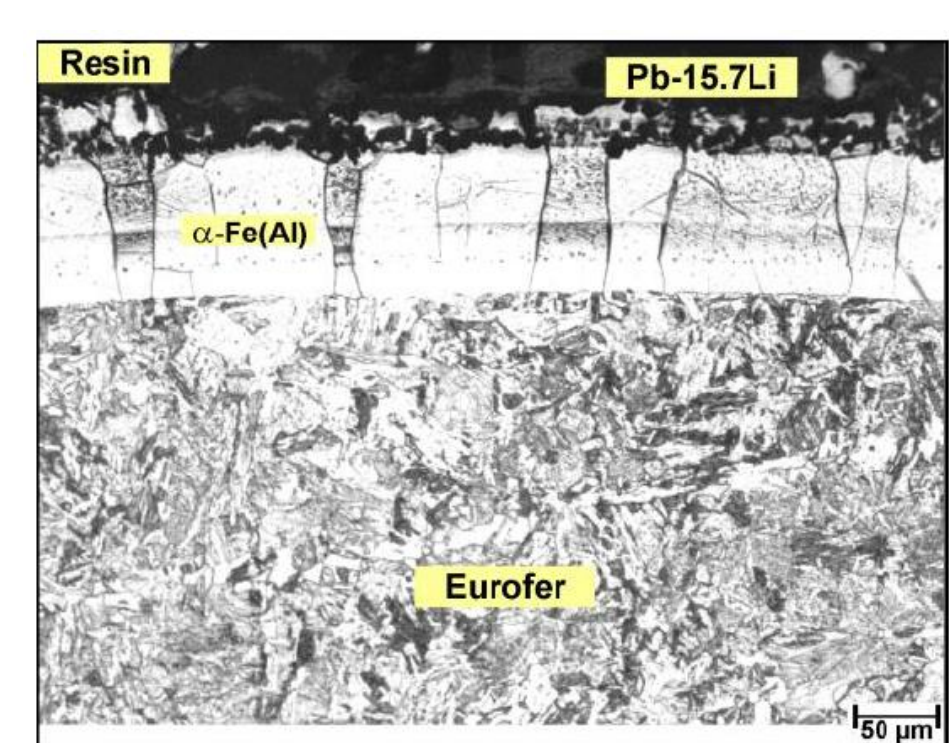

HDA coated Eurofer sample after exposure in flowing

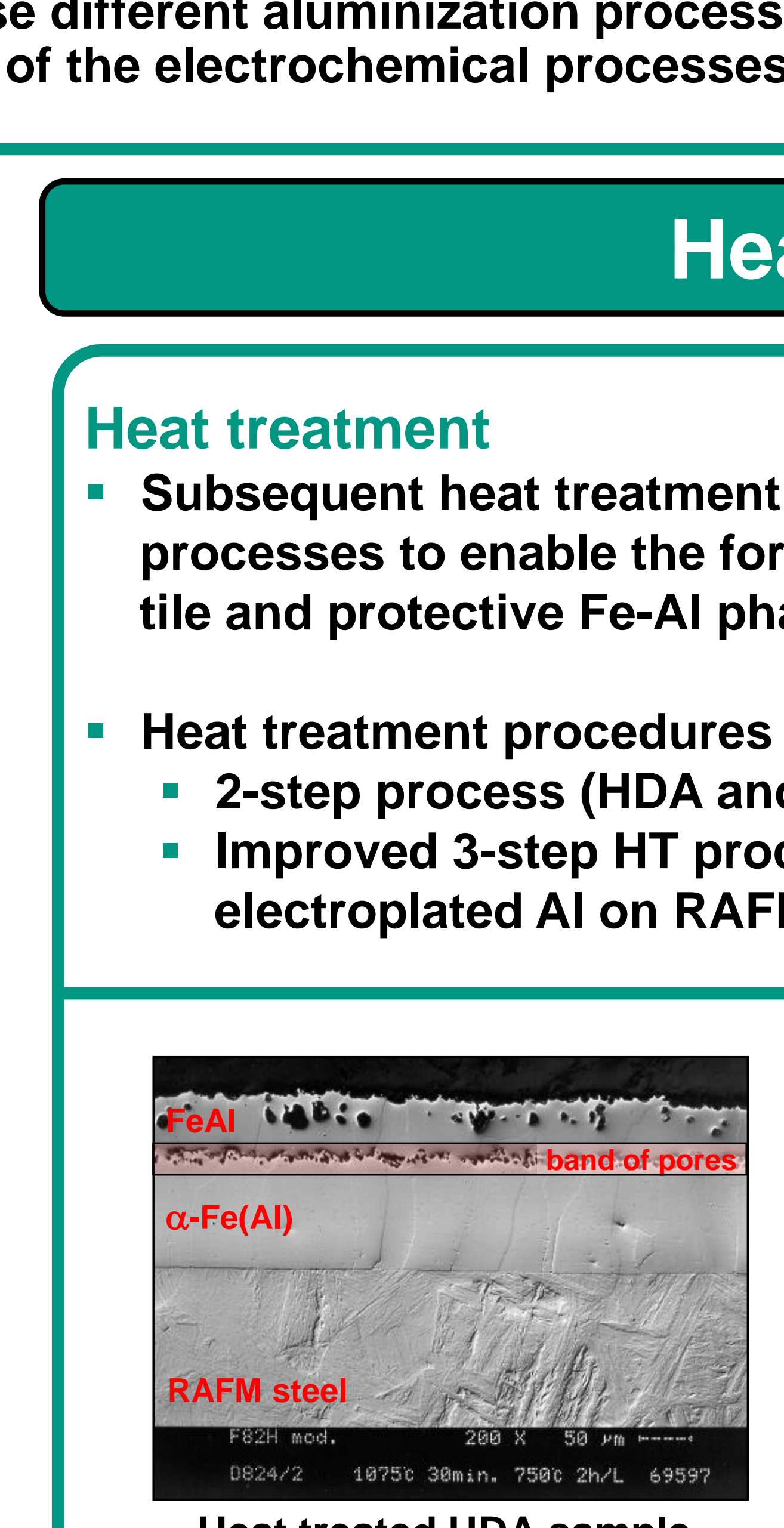

Heat treatment behavior

Heat treated HDA samp (F82H-mod.) $1075^{\circ} \mathrm{C} / 0.5 \mathrm{~h}+750^{\circ} \mathrm{C} / 2 \mathrm{~h}$

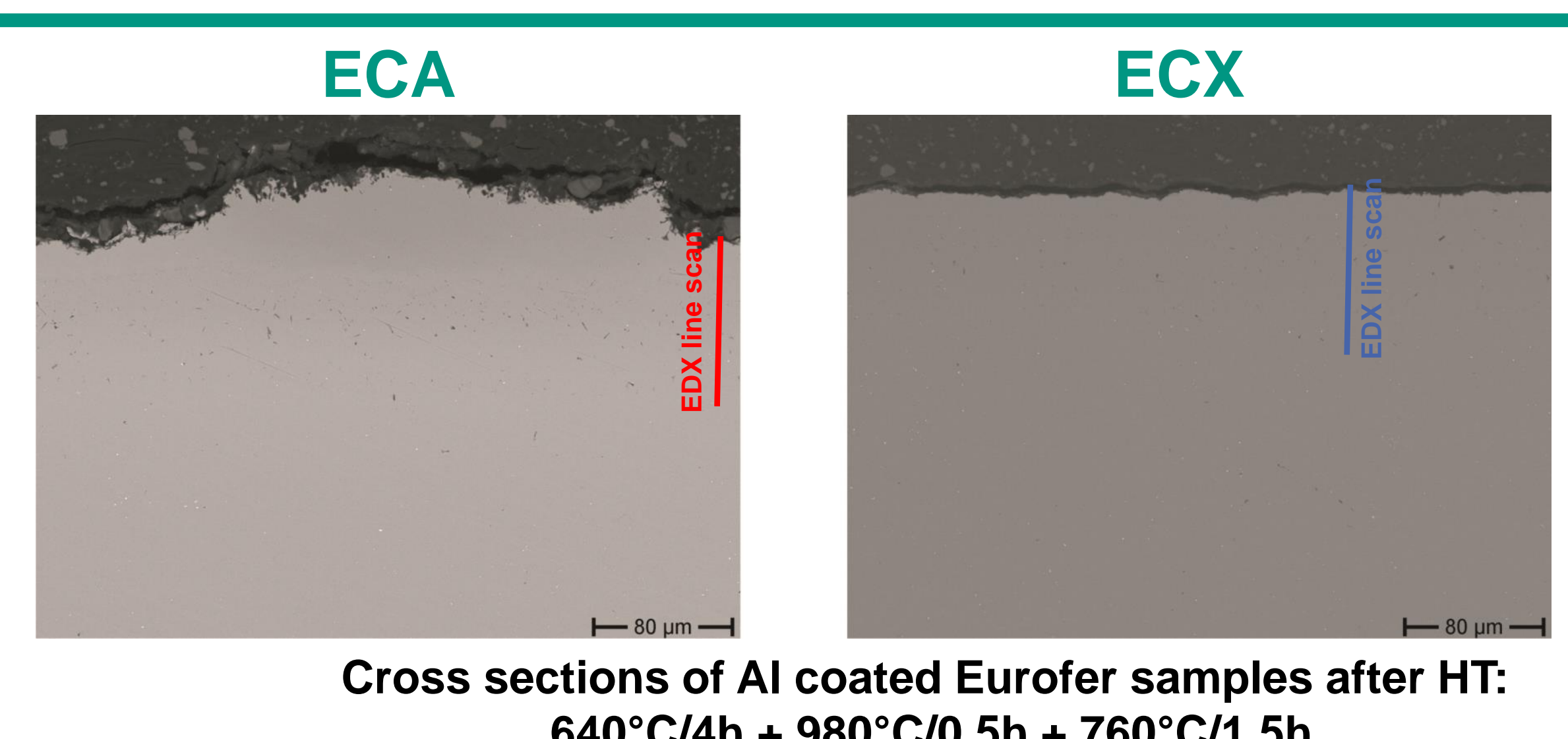

$640^{\circ} \mathrm{C} / 4 \mathrm{~h}+980^{\circ} \mathrm{C} / 0.5 \mathrm{~h}+760^{\circ} \mathrm{C} / 1.5 \mathrm{~h}$

ECA and ECX samples after HT

- Aluminum layer converted completely to ductile FeAl and $\alpha-\mathrm{Fe}(\mathrm{Al})$ phases

- No pores observable after HT in cross sections of ECA and ECX coated samples

- Overall scale thickness below $90 \mu \mathrm{m} \rightarrow$ lower amounts of Al (low activation criteria)

- Could be reduced in future by applying thinner Al layers

Surface of ECX plated sample is smoother and even compared to ECA sample Presumably due to initially coarse crystalline surface after deposition by ECA

\section{Conclusions}

Electrochemical processes ECA and ECX are suitable for Al deposition on RAFM steels and exhibit advantages compared to HDA process:

- Controllable, uniform layer thickness even at more complex shaped parts

$\rightarrow$ Thinner Al coatings possible $\rightarrow$ Reduced scale thicknesses after HT $\rightarrow$ Lower

amounts of Al (low activation)

$\Rightarrow$ No or less pore formation observable after subsequent heat treatment

ECX process favorable to ECA process

$\Rightarrow$ Lower safety requirements $\rightarrow$ might lead to lower costs

$\Rightarrow$ More flexible in adjusting process parameters (due to larger current density range)

Use of pulse plating possible $\rightarrow$ Improved Al coatings possible: Lower thicknesses,

fine grained (microcrystalline) Al layers + improved surface morphologies after HT

Testing of scale properties made by ECA and ECX is necessary

$\Rightarrow$ Corrosion tests in flowing $\mathrm{Pb}-15.7 \mathrm{Li}$ (PICOLO) are in progress (ECA, ECX)

T-permeation behavior tests are still lacking for ECA and ECX coated RAFM steels 